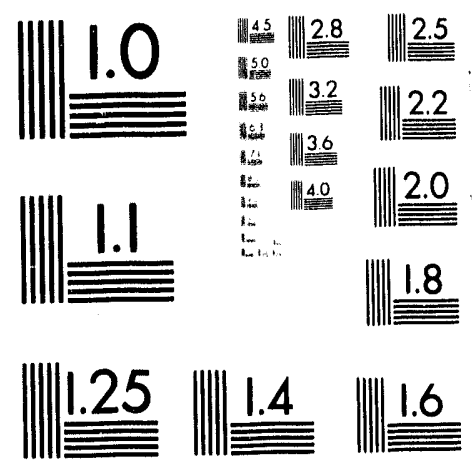



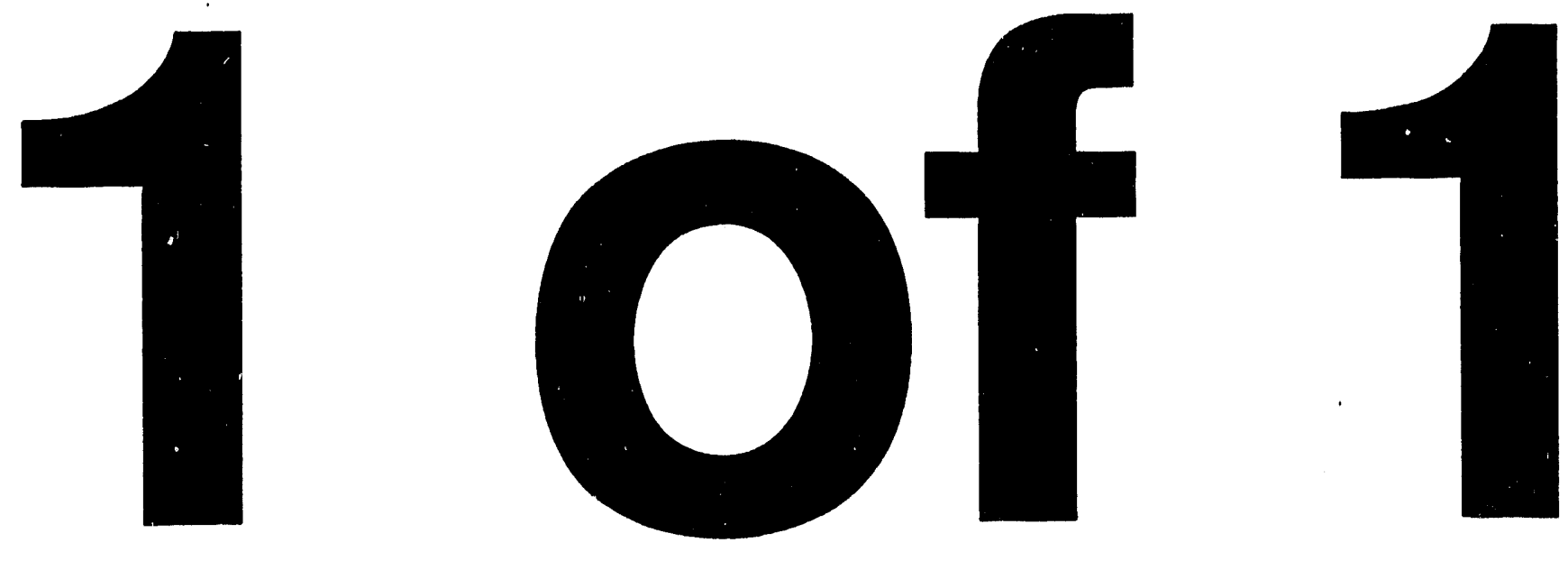


\section{Analysis of Data from Electric and
Hybrid Electric \\ Analysis of Data from Electric a
Hybrid Electric Competitions}

$$
\text { Conf } 940242--1
$$

Keith B. Wipke

National Renewable Energy Laboratory

Nicole Hill

Robert P. Larsen

Argonne National Laboratory

Prepared for the 1994 SAE International Congress and Exposition, Detroit, Michigan, February 28 - March 3, 1994

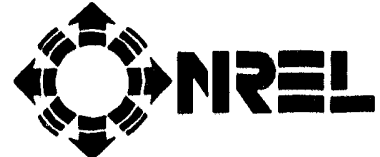

National Renewable Energy Laboratory 1617 Cole Boulevard Golden, Colorado 80401-3393

A national laboratory of the U.S. Department of Energy Operated by the Midwest Research Institute for the U.S. Department of Energy under Contract No. DE-AC02-83CH10093 


\section{NOTICE}

NOTICE: This report was prepared as an account of work sponsored by an agency of the United States government. Neither the United States government nor any agency thereof, nor any of their employees, makes any warranty, express or implied, or assumes any legal liability or responsibility for the accuracy. completeness, or usefulness of any information, apparatus, product, or process disclosed, or represents that its use would not iniringe privately owned rights. Reference herein to any specific commercial product, process, or service by trade name, trademark, manufacturer, or otherwise does not necessarily constitute or imply its endorsement, recommendation, or favoring by the United States government or any agency thereof. The views and opinions of authors expressed herein do not necessarily state or reflect those of the United States government or any agency thereof.

\section{Printed in the United States of America Available from:}

National Technical Information Service

U.S. Department of Commerce

5285 Port Royal Road

Springfield, VA 22161

Price: Microfiche A01

Printed Copy $\mathrm{AOS}$

Codes are used for pricing all publications. The code is determined by the number of pages in the publication. Information pertaining to the pricing codes can be found in the current issue of the following publications which are generally available in most libraries: Energy Research Abstracts (ERA); Government Reports Announcements and Index (GRA and I); Scientific and Technical Abstract Reports (STAR); and publication NTIS-PR-360 available from NTIS at the above address. 


\title{
Analysis of Data from Electric and Hybrid Electric Vehicle Student Competitions
}

\author{
Keith B. Wipke \\ National Renewable Energy Laboratry \\ Nicole Hill and Robert P. Larsen \\ Argonne National Laboratory
}

\begin{abstract}
The U.S. Department of Energy sponsored several student engineering competitions in 1993 that provided useful information on electric and hybrid electric vehicles. The electrical energy usage from these competitions has been recorded with a custom-built digital meter installed in every vehicle and used under controlled conditions. When combined with other factors, such as vehicle mass, speed, distance traveled, battery type, and type of components, this information provides useful insight into the performance characteristics of electrics and hybrids. All the vehicles tested were either electric vehicles or hybrid vehicles in electric-only mode, and had an average energy economy of $7.0 \mathrm{~km} / \mathrm{kWh}$. Based on the performance of the "ground-up" hybrid electric vehicles in the 1993 Hybrid Electric Vehicle Cnallenge, data revealed a $1 \mathrm{~km} / \mathrm{kWh}$ energy economy benefit for every $133 \mathrm{~kg}$ decrease in vehicle mass. By running all the electric vehicles at a competition in Atlanta at several differen constant speeds, the effects of rolling resistance and aerodynamic drag were evaluated. On average, these vehicles were $32 \%$ more energy efficient at $40 \mathrm{~km} / \mathrm{h}$ than at $72 \mathrm{~km} / \mathrm{h}$. The results of the competition data analysis confirm that these engineering competitions not only provide an educational experience for the students, but also show technology performance and improvements in electric and hybrid vehicles by setting benchmarks and revealing trends.
\end{abstract}

\section{INTRODUCTION}

The U.S. Department of Energy (DOE), through the Center for Transportation Research at Argonne National Laboratory (ANL), has sponsored Engineering Research Competitions (ERCs) across the nation since 1987. These competitions have involved high schools, vocational schools, community colleges, and universities. Each year the level of student involvement increases along with the technical objectives of the competitions. In 1993, DOE sponsored one hybrid electric vehicle (HEV) and three electric vehicle (EV) competitions, the subjects of this paper, a dedicated natural gas vehicle competition, and the alcohol-fueled classes in Formula SAE an SAE Supermileage. Over 100 different schools participated in these competitions. This year the EV competitions covered the Southwest, Southeast, and Northeast regions of the United States. Teams from all over North America, including two teams from Canada, participated in the HEV competition in Dearborn, Michigan.

The competitions have been a cooperative effort between government, industry, and academia. These competitions have increased awareness of alternative transportation technologies atic laid the foundation for collecting data on these technologies. This year, DOE implemented the use of kilowatt-hour meters for data collection during the competitions. These data acquisition meters were donated by DOE to each of the student teams participating in the competitions as part of an ongoing effort to encourage the schools to continue research in the areas of alternative transportation technologies. The student teams were supplied the meters, shunts, and batteries for the meters. Most teams installed the simple, cost-effective meters before the competition and were ready to collect data before it started. This enabled some teams to learn how to drive their vehicles efficiently prior to the start of the events, allowing them the opportunity to perform better in the overall competition.

State-of-the-art technology is demonstrated in the competitions with events highlighting range, acceleration, and efficiency. The basics of the practicality, design, manufacturability, associated costs, and ergonomics of the vehicles were also covered in the competitions, which included oral design presentations. Though the majority of the vehicles used lead-acid batteries and DC motors and controllers, this commercially available technology is showing improvements in performance and reliability. Some of the emerging technologies were revealed at the American Tour de Sol and the 1993 HEV Challenge, displaying promise for the future. The results from the American Tour de Sol, along with detailed event descriptions, have already been presented at a recent Northeast Sustainable Energy Association conference [1], so only the performance of a few representative vehicles will be discussed here.

While the vehicles themselves are normally the focus of these competitions, the charging facilities for electric and hybrid vehicles are also being developed at a fast pace. 
Although still in the developmental stages, the charging facilities used in these competitions included such new devices as the $208 \mathrm{~V}, 30 \mathrm{~A}$, single-phase individual charging meter, developed by Detroit Edison.

\section{BRIEF DESCRIPTION OF THE ENERGY METER}

Electrical efficiency data collected in earlier DOE-sponsored EV competitions used an approach developed for the American Tour de Sol in 1991 employing multimeters and a clamp-on current probe to measure average battery pack voltage and average current [1]. A more accurate and permanent probe to record energy efficiency was desired, leading to the development of the energy usage meter used in the 1993 competitions. A kilowatt-hour meter was custom built for ERCs by Cruising Equipment Company according to ANL specifications [2].

The data acquisition unit measured $11.3 \mathrm{~cm}$ $\times 10.1 \mathrm{~cm} \times 4.0 \mathrm{~cm}$, making it suitable for installation in dashboards or elsewhere in the passenger compartment (see Figure 1). The unit recorded the elapsed time and measured two input signals: battery pack voltage and electric current to or from the battery pack. It used this information to calculate the amount of energy running into the batteries (charging and regenerative braking) or out of the batteries (power used to propel vehicle) through a numeric integration. The voltage and current were sampled at $1.2 \mathrm{kHz}$ with averages computed every 128 samples for the energy calculation. The voltage, electrical current, and net energy used were also sent every second to the RS-232 connector through the external port. The current was measured through a shunt with the ratio of $500 \mathrm{~A}$ to $50 \mathrm{mV}$. The voltage was measured by reducing it with a voltage divider on the bus connector [3].

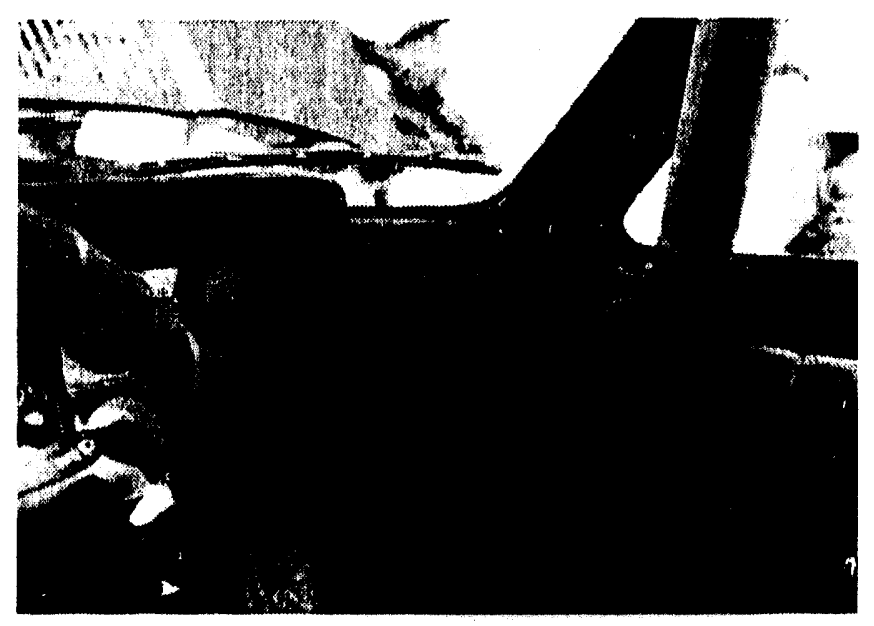

Figure 1. Photograph of the energy meter, Phoenix.

The unit had a numeric LCD to display the voltage, current, or net energy used by means of a three-way switch. Capturing the temporal data required a laptop computer with appropriate software that stored all the information from the serial port. Because of the expense and weight of portable computers, only a few schools used an on-board computer to capture this information. Figure 2 shows temporal data from a 25-lap run by Cortez High School at the Phoenix competition as an example. Notice how the current was used in short bursts, except for the end of the run when the driver had the vehicle under full power for the final five laps. Although the instantaneous power varied continuously, the net energy used (with the negative indicating energy extracted from the batteries) appeared to increase linearly because of the small scale on the graph. This means that the time-averaged power was almost constant at $22 \mathrm{~kW}$. Another interesting feature of this graph is that it shows the effect of the electrical load on the battery pack voltage. This particular vehicle started out with an open-circuit voltage of $102 \mathrm{~V}$, and the battery pack voltage was reduced to $82 \mathrm{~V}$ when the electrical load was applied. The graph also clearly shows the battery pack voltage increasing with decreased electrical load, as the vehicle exited the race track and went from a low of $70 \mathrm{~V}$ back up to $90 \mathrm{~V}$.

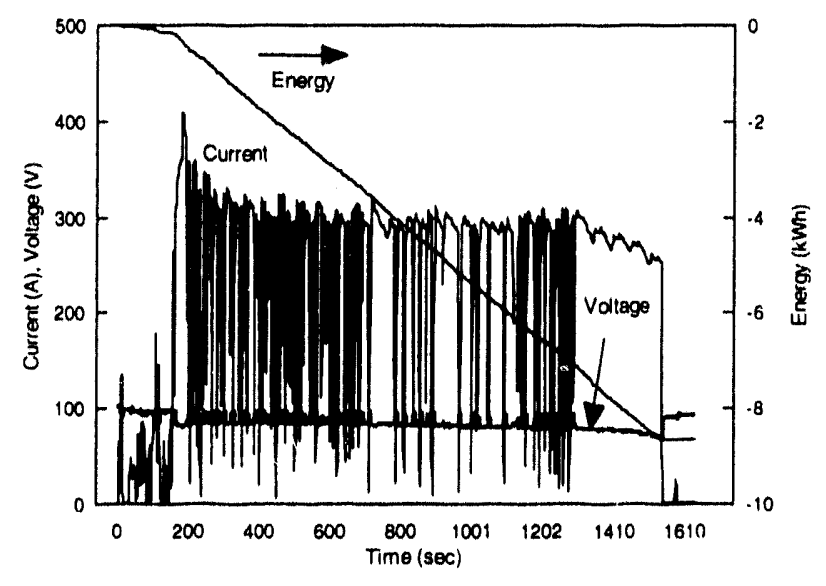

Figure 2. Sample temporal data taken from Cortez High School, Phoenix.

\section{DESCRIPTION OF THE COMPETITIONS: PHOENIX, ATLANTA, DEARBORN, AND AMERICAN TOUR DE SOL.}

\section{APS Solar \& Electric 500, Phoenix}

Phoenix was the setting for the 1993 APS Solar \& Electric 500, the first of the year's ERCs sponsored by DOE, held March 5 and 6. One New Mexico and 25 Arizona high school teams converted gasoline cars and trucks into EVs. The DOE student engineering competitions use static and dynamic events to educate students in currently available electric vehicle technology.

The two-day competition included static events, such as the Oral Presentations and Design Event, and dynamic events including the Energy Efficiency Event, Range Event, and Acceleration/Braking Event. Both types of events were incorporated to display the full range of students' involvement with their vehicle projects. The static events allowed the students the opportunity to work on their communication and analytical skills, while the dynamic events allowed them to test their vehicle designs and discover the satisfaction of seeing a project to its completion.

Vehicles were built to meet the technical specifications of the 1993 Phoenix Solar \& Electric 500 Rules, 
which focused on the basics of electric vehicle technology for the high school competition class. The vehicles were limited to $96 \mathrm{~V}$ lead-acid battery packs, and in most cases used DC motors and controllers donated by General Electric.

The high school vehicles were not separated by vehicle type or weight. For example, half-ton pickup trucks competed against VW Rabbits. To help compensate for the weight difference of the vehicles, a rule of thumb based on experimental results was applied to the points available in the Efficiency Event. For every $10 \%$ decrease in vehicle weight, a $7 \%$ increase in efficiency was expected. A recent article on weight-cutting efforts claims that, in practice, a $10 \%$ weight reduction results in a $3 \%$ to $6 \%$ fuel economy benefit for conventional vehicles [4]. The weight factor for each vehicle was caiculated as

$$
\text { Weight Factor }=\left[\frac{\text { Vehicle Weight }}{\text { Average Vehicle Weight }}\right] \times 0.7+0.3
$$

Each vehicle's energy economy was divided by this factor, which could be greater or less than one. The average competition vehicle weight was used as the baseline for this equation in the Efficiency Event. The vehicle data used for this weight factor is listed in Table Al of the Appendix.

After each vehicle successfully completed the safety and technical inspections, the next step was the Acceleration/Braking Event. The acceleration times indicated performance characteristics of the vehicles. The event itself covered $0.40 \mathrm{~km}$, subdivided into a $0.20 \mathrm{~km}$ acceleration run and a $0.20 \mathrm{~km}$ braking distance. The time required to complete the total distance was u.ed to score this event.

The Range Event measured the farthest distance traveled by a vehicle at a constant speed in 1 hour. A pace car led the single-file line of vehicles around the track at a speed of $88.5 \mathrm{~km} / \mathrm{h}$ for the entire event, with no passing allowed. The actual average speed over the hour-long event was $81 \mathrm{~km} / \mathrm{hr}$ because the first few laps were used to get the vehicles up to speed. As vehicles lost energy and slowed below the required speed, they had to leave the track. The number of laps, elapsed time, and energy used was recorded for the vehicles as they left the track. Unfortunately, some confusion with the flagmen occurred when gaps between the vehicles were formed. As a result, two vehicles were flagged off prematurely and were not allowed to reenter the track. The range of these two vehicles was adjusted to compensate for their premature exit on the basis of their energy readings and those of the other vehicles which ran until their energy was depleted. For future competitions, this situation could be alleviated by using a radar gun, requiring accurate speedometers, and allowing passing under controlled conditions

The Efficiency Event was scored by using the raw data from the meters and the distance traveled during the Range Event to calculate the distance per amount of energy used. The vehicle that demonstrated the most efficient use of energy, after applying the weight factor discussed earlier, won the Efficiency Event.

The Phoenix competition provided a testing ground for the meters and determined the best overall performing vehicle. Despite a short delivery schedule and installation period for the meters, the high schools did an outstanding job incorporating them into the vehicles. The information from the meters proved invaluable for the other electric vehicle competitions that followed.

\section{Clean Air Grand Prix, Atlanta}

The Atlanta Clean Air Grand Prix, held in conjunction with the Clean Air Exposition on May 13, 14, and 15 was a collegiate EV competition. Fourteen teams of universities, community colleges, and technical schools from the Southeast were invited to participate, making it the first electric vehicle competition held in that region of the United States. Of these fourteen schools, three were historically black colleges. Most of the teams had from January until May to design and convert their vehicles to run on electric power. Because of the short amount of preparation time, only ten of the teams competed in the Grand Prix. The Clean Air Vehicle Association (CAVA) put together the Clean Air Grand Prix to educate the public and the students on electric vehicles, as well as to add flair to the exposition.

CAVA worked with a number of sponsors to have most of the itenus donated to all the teams, including the vehicles, batteries, tires, motors, controllers, and the energy meters. Trojan Battery Company provided the batteries, General Electric provided the motors, controllers, and technical support for the teams, and Arena Auto Auctions donated suitable cars to the teams. CAVA developed a set of rules and technical specifications based on the Sports Car Club of America's touring rules. All teams were limited to the $120 \mathrm{~V}$ battery packs and DC motors and controllers. While there were no pickup trucks in this competition, the donated vehicles, varied in model, style, and weight (see Table A2 for detailed Atlanta competition vehicle data). Because the teams had no say in the vehicle they received, normalizing the vehicle weights was important in scoring the events affected by this factor. The variation in the weight of the vehicles was compensated for by using Equation 1.

The structure of the Atlanta competition was similar to the one in Phoenix with a layout that included acceleration, range, electrical efficiency, design review, and oral presentations. However, ANL personnel worked closely with the event organizers and had input into the type of data collected and the manner in which it was collected. For example, the Acceleration Event was modified to include a five-lap solo event, and the Efficiency Event was separated from the Range Event. This allowed for data collection at three separate constant speeds, with additional control over collection methods.

The Acceleration/Solo Event added a five-lap solo run to the $0.20 \mathrm{~km}$ acceleration run. The solo portion tested the performance of each vehicle and allowed drivers time alone on the track to test their vehicles without the complication of passing. The $0.20 \mathrm{~km}$ acceleration run was held on a $1.42 \mathrm{~km}$ road track at the Atlanta Motor Speedway. In addition to the track times, kilowatt-hour readings were recorded for each vehicle. This provided a history of energy usage for each 
vehicle, to be used as a backup in case any problems with the meters occurred during other events.

The Range Event used the same road course as the Acceleration/Solo Event. The layout of the course did not lend itself to the type of pace car setup used in Phoenix. Instead, the vehicles had a time limit of 2 hours and a minimum lap speed of $40 \mathrm{~km} / \mathrm{h}$. This gave the teams greater flexibility with their individual driving strategies. Passing was allowed only on the straightaways, and vehicles were allowed to pull off the track and reenter at any time during the 2 hour limit.

The Efficiency Event measured the energy consumption of the vehicles at three distinct, constant speeds. A pace car led the vehicles around the $2.4 \mathrm{~km}$ oval for a total of five laps at $72 \mathrm{~km} / \mathrm{h}$ and $56 \mathrm{~km} / \mathrm{h}$ and three laps at $40 \mathrm{~km} / \mathrm{h}$. The meters were read just before and just after each group of laps was driven.

\section{Hybrid Electric Vehicle Challenge, Dearborn}

The 1993 HEV Challenge, held June 1-5, was the first in a series of competitions focusing on the emerging technologies associated with hybrid electric vehicles. These vehicles combine the best features of the liquid-fuel-powered vehicle and the electric vehicle while offering the range and performance provided by conventional vehicles. HEVs also provide an emissions-free option for zero emissions zones. Thirty colleges and universities designed and built parallel or series hybrid vehicles for the competition. The teams had the choice of building a vehicle from the ground up (Ground-Up Class) and receiving $\$ 10,000$ in seed money, or converting a donated 1992 Ford Escort Wagon to a hybrid vehicle (Escort Conversion Class). Eighteen of the teams selected chose to convert Escorts while the remaining 12 teams built vehicles from the ground up (see Table A3 and A4 for details on the hybrid strategy and components used for the Ground-Up and Escort Conversion classes, respectively). The teams participated in a five-day competition that covered qualifying (See Figure 3), emissions testing, acceleration, range, vehicle efficiency, a simulated commuter event, oral presentations, design reviews, and cost assessments. All aspects of vehicle design, construction, and performance were judged and scored. Twenty-six out of the $30 \mathrm{HEVs}$ completed that portion of the Challenge.

One major goal of the HEV Challenge was to explore efficient vehicle propulsion systems. Events were specifically designed to determine the overall efficiency, electrical efficiency, and alternative power unit (APU) efficiency of the vehicles by rieasuring the fuel consumption and energy usage throughout the competition. The Electrical Efficiency Event, for example, required the teams to meet a minimum electric-only or zero emission vehicle (ZEV) range requirement of $32.2 \mathrm{~km}$ while determining which electrical system functioned most efficiently without using the APU. The kilowatt-hour meters, charging stations, and ZEV events were used for this purpose [5]. The Range Event was divided into four segments: a $32.2 \mathrm{~km}$ portion around a track at the Dearborn Proving Grounds (DPG), followed by a $129.4 \mathrm{~km}$ HEV portion on public streets where the APU could be on, followed by ZEV and/or HEV driving modes on the track at Michigan International Speedway (MIS). Efficient charging schemes and skillful driving were encouraged by measuring the kilometers driven per kilowatt-hour of energy consumed. A loss factor representing energy losses in the vehicle charging systems was applied in computing the electrical efficiency results.

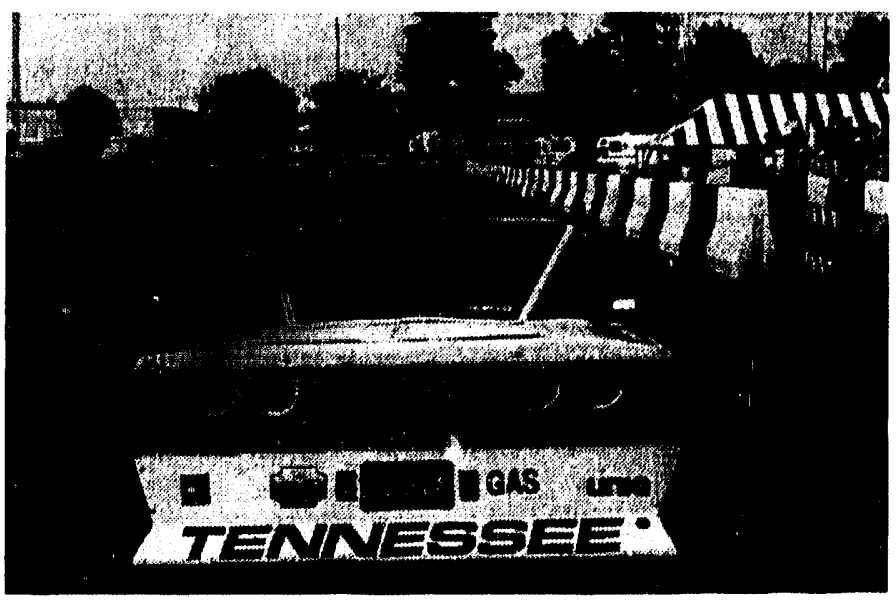

Figure 3. Photograph of the University of Tennessee vehicle at the acceleration qualifying event, Dearborn.

\section{American Tour de Sol}

The focus of the American Tour de Sol is educating the general public on alternative renewable energies available for transportation. The first Tour de Sol included solar cars and electric vehicles that were very different in construction and appearance. This year the competition involved over thirty vehicles ranging from solar cars to prototype EVs and included the first HEV to participate in the six day rally (see Table A5 Sor vehicle data from the Tour de Sol). Tour de Sol started in Boston, MA and ended up in Burlington, VA. The rally included check points and time limitations for each portion of the route, with extra points given for additional miles completed at the end of each leg of the rally. The kilowatt-hours were recorded at the beginning and end of each day, along with the total distance traveled by each vehicle. By the end of the week, all but two teams had their meters working. The teams with AC systems had difficulty with the meter operating properly. The sensitivity of the meter to voltage and current inputs and the electrical noise of the $\mathrm{AC}$ motor and controller both contributed to the problems encountered with the data collection.

The American Tour de Sol, being the longest running competition of its kind, has many repeat competitors. While the improvements in EV technology are recorded eacn year, the difficult terrain presents the opportunity to observe the reliability of these electric vehicles. The majority of the vehicles used lead-acid battery technology and demonstrated a repeatable range of $129 \mathrm{~km}$ each day. Many of the vehicles with advanced battery technology (Zinc Bromine and NiCad) displayed ranges of $241 \mathrm{~km}$ or more. The American Tour de Sol is a proving ground for many student-based electric vehicles. 


\section{RESULTS OF ANALYSIS}

\section{Open-Circuit Voltage Drop vs. Distance in Lead-Acid Battery Packs}

The open-circuit voltage drop in lead-acid battery packs was measured as a function of the number of kilometers driven by the EVs during the Phoenix competition. In lead-acid batteries, the open-circuit voltage decreases as a function of state-of-charge (SOC). The open-circuit voltage of each vehicle was measured prior to its starting an event and again just after the vehicle had pulled off of the track. As expected, the open-circuit voltage was still changing with time when the vehicles were checked after pulling off the track. This is primarily caused by the batteries recovering from such a rapid discharge, and involves a combination of the batteries cooling down and the chemistry in the batteries returning to equilibrium. For consistency, the voltage was measured immediately after the vehicle stopped moving; however, this was not possible when multiple vehicles exited the track simultaneously.

As shown in Figure 4, the voltage drop was generally larger the farther the vehicle traveled, but there is scatter caused by differences in vehicle mass, vehicle efficiency, initial SOC, rate of discharge, and battery manufacturer. However, the data does indicate the expected trend of increasing battery pack voltage drop with increasing distance traveled. All of the EVs at Phoenix had lead-acid battery packs rated at $96 \mathrm{~V}$, so the data in Figure 4 show a battery pack open-circuit voltage drop of between $3 \%$ and 18\% (see Table A6 for event data for Phoenix, Atlanta, and Dearborn).

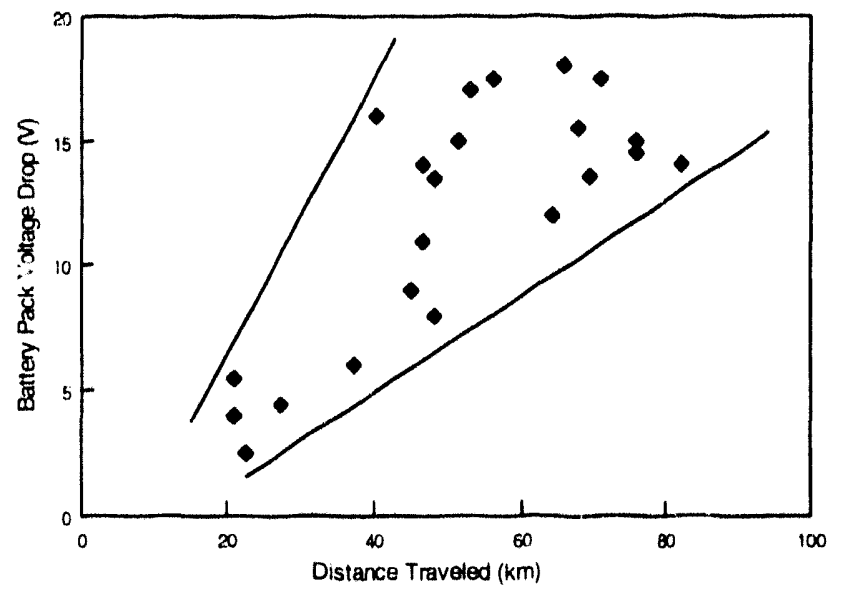

Figure 4. Open-circuit voltage drop in lead-acid battery packs vs. distance, Phoenix.

\section{Effect of Vehicle Mass}

At all of the competitions, the vehicles were weighed with four electronic scales, one placed under each wheel, to measure the weight and mass and to determine the mass distribution. Coupling the vehicle mass with its energy economy, defined as distance traveled divided by energy used, provided insight into the significant effect of vehicle mass on electric and hybrid vehicles. At the HEV Challenge in Dearborn, the vehicles which most clearly showed this effect were the Ground-Up hybrids, as these vehicles displayed considerable spread $(588 \mathrm{~kg}$ ) in vehicle mass. Because the Escort Conversion vehicles had a maximum vehicle mass allowed by the rules and regulations (gross vehicle weight rating $+10 \%$ ), their masses were concentrated around this specification with only a $234 \mathrm{~kg}$ spread (see Table 1, noting that only vehicles from the three competitions which competed and provided accurate meter readings are included in this analysis). The difference in the components and designs of the Escort Conversion vehicles proved more significant than the small difference in the vehicles' mass.

Table 1. Vehicle mass

\begin{tabular}{|c|c|c|c|c|}
\hline Competition & $\begin{array}{c}\text { Min. Mass } \\
(\mathbf{k g})\end{array}$ & $\begin{array}{c}\text { Max. } \\
\text { Mass (kg) }\end{array}$ & $\begin{array}{c}\text { Spread } \\
\text { (kg) }\end{array}$ & $\begin{array}{c}\text { Avg. } \\
(\mathbf{k g})\end{array}$ \\
\hline $\begin{array}{c}\text { Dearborn } \\
\text { (Ground-Up) }\end{array}$ & 1,062 & 1,650 & 588 & 1,306 \\
\hline $\begin{array}{c}\text { Dearborn } \\
\text { (Escort } \\
\text { Conversion) }\end{array}$ & 1,614 & 1,848 & 234 & 1,695 \\
\hline Atlanta & 1,023 & 1,703 & 680 & 1,358 \\
\hline Phoenix & 1,307 & 1,645 & 338 & 1,446 \\
\hline
\end{tabular}

Figure 5 shows energy economy plotted against mass for the Ground-Up vehicles at Dearborn during the first ZEV portion of the Range Event. There are also many differences between these vehicles in addition to the mass, such as differing components, body aerodynamics, and tires. However, because the heaviest vehicle had a mass $55 \%$ higher than the lightest vehicle, and the vehicles were not traveling at high speeds, the large difference in mass dominates the differences in component efficiencies. A linear interpolation showed a $1 \mathrm{~km} / \mathrm{kWh}$ increase in energy economy for every $133 \mathrm{~kg}$ decrease in vehicle mass. A detailed discussion of the benefits of lightweight hybrid vehicles is given by Lovins, Barnett, and Lovins [6].

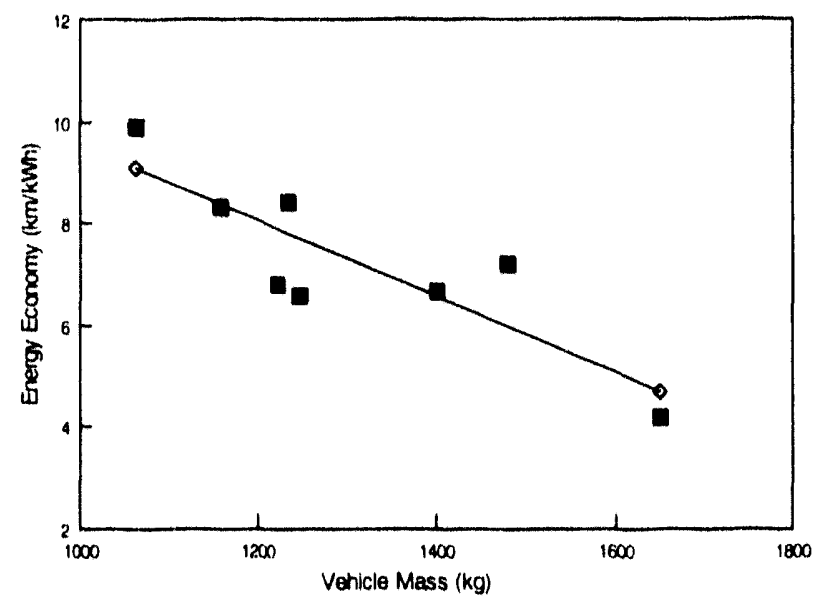

Figure 5. Energy economy vs. mass for Ground-Up HEVs, Dearborn. 
As previously discussed in the description of the competitions, the Atlanta competition provided an ideal setting to examine the effect of mass and speed. The three runs at 72,56 , and $40 \mathrm{~km} / \mathrm{h}$ provided energy usage data for a fixed distance around a $2.4 \mathrm{~km}$ track. The difference between the most and least massive electric vehicles at Atlanta was $680 \mathrm{~kg}$. With the exception of the data from one vehicle at $1250 \mathrm{~kg}$. Figure 6 shows a relatively smooth curve, with the lightest vehicles having the highest energy economy and the heaviest vehicles having the lowest energy economy. The three symbols arranged in a vertical line are from the same vehicle at the three different speeds.

All of the Atlanta vehicles were conversions, but the major differences in mass were of similar magnitude to the Ground-Up HEVs and had more effect than other differences in the vehicles. For current conventional U.S. cars, fuel economy is about equally sensitive to reductions in drag and rolling resistance, but is nearly three times as sensitive to reductions in mass $[7,6]$. Because the Atlanta vehicles were all conversions from conventional vehicles, it is not surprising to see a similar sensitivity to mass displayed in Figure 6.

Another notable feature of the Atlanta competition was that sponsors provided the same components to all vehicles, with the exception of the battery manufacturer sponsor, which allowed the schools to select the battery type most suitable for meeting their goals. Some teams selected batteries which provided optimal power and acceleration, whereas other schools favored increased energy capacity and driving range.

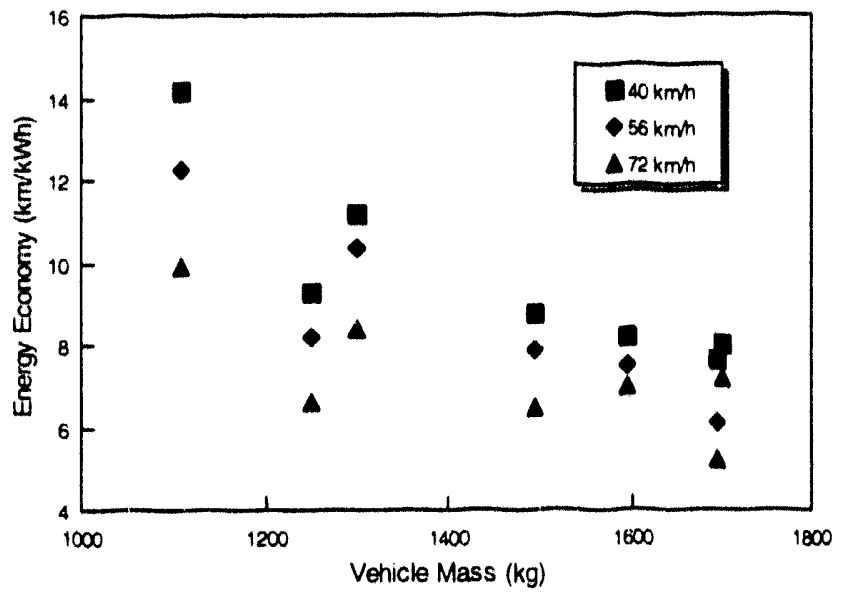

Figure 6. Energy economy vs, mass, Atlanta.

Although the effect of vehicle mass was found to be significant in all three competitions, the data from Phoenix does not indicate this as clearly as the other competitions because of the nature of that event. At Phoenix, all the vehicles had to maintain a constant speed of $88.5 \mathrm{~km} / \mathrm{h}$ behind a pace vehicle. If a vehicle started lagging behind, it was flagged off of the track. Therefore, the Phoenix data is not as representative of how much energy the vohicles were carrying as it would have been if they had been allowed to drive until their batteries were depleted. Aerodynamic drag also played a larger part in Phoenix because of the relatively high speed $(81 \mathrm{~km} / \mathrm{h})$ at which the vehicles were driven. Additionally, the difference between the most and least massive vehicles was not as large as in the other two competitions. At Atlanta and Dearborn, however, there was a good correlation between vehicle mass and energy economy, as has already been discussed.

\section{Effect of Vehicle Speed}

In addition to showing the effect of vehicle mass, Figure 6 also reveals the effect of different vehicle speeds with the three vertically spaced symbols. It is interesting to note how much more the lightest vehicle was affected by aerodynamic drag than the heaviest vehicle, as judged by the vertical distance between symbols. This is because the lighter vehicle is spending a larger percentage of its power on overcoming aerodynamic losses than it is in overcoming rolling resistance. Therefore, the effect of vehicle speed on energy economy is more pronounced for lighter vehicles than for heavier vehicles for a constant speed. The primary forces involved are

$$
F_{\text {total }}=F_{\text {roll }}+F_{\text {aero }}=f m g+\frac{1}{2} \rho C A v^{2}
$$

where $f$ is the coefficient of rolling resistance, $C$ is the coefficient of aerodynamic drag, $A$ is the frontal area, and $\rho$ is the air density [8]. This equation shows that the rolling resistance is proportional to the vehicle mass $(m)$ while the aerodynamic drag increases by the square of the velocity. When the energy economy is plotted against vehicle speed rather than mass, the effect of the speed on energy economy becomes easier to see, as shown in Figure 7. The energy economy has been normalized at $40 \mathrm{~km} / \mathrm{h}$, so that the ratio at $40 \mathrm{~km} / \mathrm{h}$ is 1 , while the ratic at $72 \mathrm{~km} / \mathrm{h}$ is the energy economy at $72 \mathrm{~km} / \mathrm{h}$ divided by the energy economy at $40 \mathrm{~km} / \mathrm{h}$.

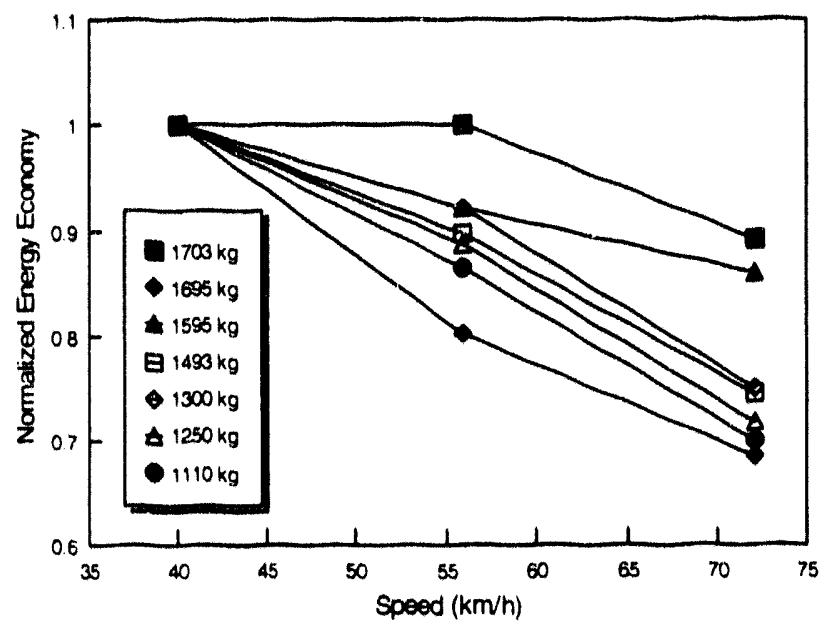

Figure 7. Normalized energy economy vs. speed, Atlanta.

All of the vehicles showed a decrease in energy economy as the vehicle speed was increased, except for the $1703 \mathrm{~kg}$ vehicle which stayed the same between 40 and $56 \mathrm{~km} / \mathrm{h}$. More importantly, Figure 7 clearly shows how the lighter vehicles experienced a larger percentage decrease in energy economy compared with the heavier vehicles 
(30\% decrease vs, $11 \%$ decrease). The exception was the one outlying vehicle that had a mass of $1695 \mathrm{~kg}$. Therefore, when it comes to highway driving, vehicle designers should consider the aerodynamic factor to be much more important in minimizing energy usage in the new lightweight vehicles than in conventional vehicles. Lovins supports this conclusion, claiming that in higher fuel economy vehicles, aerodynamic drag is more important than mass [6].

\section{Vehicle Driving Range}

The driving range of the electric and hybrid vehicles was tested in all three competitions. In Atlanta, the vehicles had 2 hours, could drive at any speed above $40 \mathrm{~km} / \mathrm{h}$, and could even stop for a period of time to let their batteries recover. In Phoenix the range was tested under the rigorous requirements of maintaining $88.5 \mathrm{~km} / \mathrm{h}$ behind a pace vehicle. Most of the teams at Phoenix could have driven much further if they had been able to slow down as their batteries became depleted, or if they had been able to drive at a slower speed over the whole time period. The time allowed at Phoenix was limited to 1 hour, and only one vehicle was able to maintain the required speed at the end of that time. In Dearborn, the vehicles had ZEV (electric only) and HEV (where the APU was switched on) portions of the Range Event, with an overall time period of 5 hours. The data summarized in the Appendix and Figure 8 represents the data from the two ZEV portions of that event only.

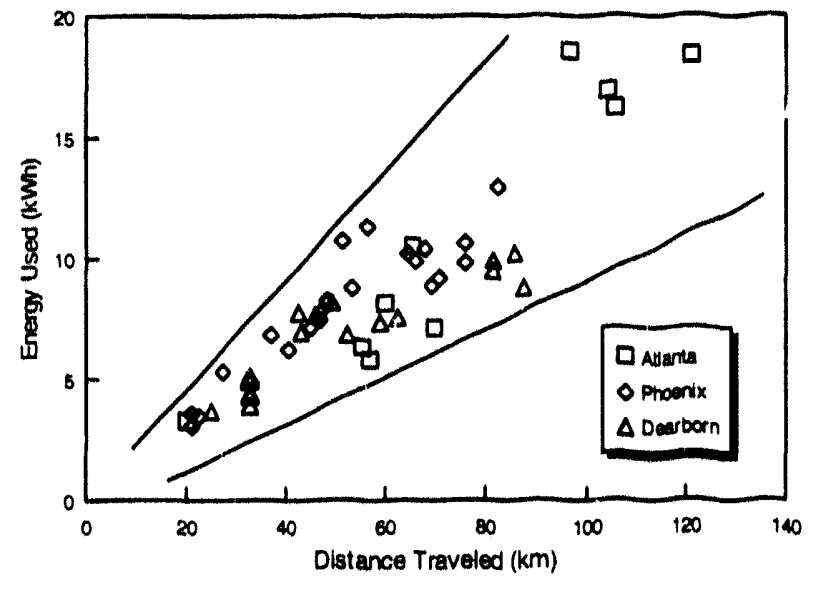

Figure 8. Electric-only range for all 3 competitions.

Figure 8 shows the electrical energy used plotted against distance traveled during the Range Event for each vehicle in the three competitions. The maximum ranges under these conditions for the best vehicles were $121.1 \mathrm{~km}$ at Atlanta, $82.0 \mathrm{~km}$ at Phoenix, and $87.9 \mathrm{~km}$ at Dearborn during the two ZEV portions. Since extended range is one of the advantages of HEVs, it should be noted that the best range achieved at Dearborn, including the APU operational mode, was $303 \mathrm{~km}$. HEVs use two sources of energy, thus complicating energy economy calculations. We will focus on the electric-only energy usage. As will be discussed in the next section, the ratio of distance traveled to energy used provides a measure of a vehicle's energy economy, which is related to how efficiently the vehicle was able to convert its stored energy into moving from one point to another.

\section{Energy Economy and Efficiency}

Energy economy, as defined in this paper, is determined by dividing the distance a vehicle travels by the amount of energy it took to travel that distance, expressed in $\mathrm{km} / \mathrm{kWh}$. While the term "economy" may seem awkward in the context of energy efficiency, it comes from the term "fuel economy," measured in $\mathrm{km} / \mathrm{L}$ of fuel, a common measure of how efficient a conventional vehicle is at converting its fuel energy into movement. Some people prefer to use $\mathrm{kWh} / \mathrm{km}$ so that the numerical values are not mistakenly compared to $\mathrm{km} / \mathrm{L}$ of fuel by the general public [9]. In any case, the ratio of distance traveled to energy used is the common way of looking at the efficiencies of electric and hybrid vehicles. For data on the energy economy of 30 commercially available electric vehicles, refer to the Electric Vehicle Directory [10].

The best energy economy demonstrated during the Phoenix Range Event was $7.75 \mathrm{~km} / \mathrm{kWh}$. During the Range Event at Atlanta, the most efficient vehicle had an energy economy of $9.72 \mathrm{~km} / \mathrm{kWh}$ in 2 hours with an average speed of $35 \mathrm{~km} / \mathrm{h}$. Because of the short length of the constant-speed efficiency runs at the three different speeds in Atlanta, their Efficiency Event should not be compared to the other competitions' Efficiency Events which involved much greater distances. However, it should be noted that the same school with the highest energy economy in the Range Event at Atlanta also showed a record high of $14.2 \mathrm{~km} / \mathrm{kWh}$ at the constant speed of $40 \mathrm{~km} / \mathrm{h}$. During the first EV portion of the Range Event at the HEV Challenge, the most efficient Ground-Up hybrid had an energy economy of $9.89 \mathrm{~km} / \mathrm{kWh}$, with the most efficient Escort Conversion demonstrating a $9.70 \mathrm{~km} / \mathrm{kWh}$ energy economy.

Most of the energy economy values obtained from the competitions are on closed-course tracks, bringing into question the correlation of these values with what would occur on public roads under normal operation. One of the strengths of the American Tour de Sol competition is that the entire rally part of the competition takes place on public roads in more than one state. Table A7 compares the University of Central Florida (UCF) vehicle during the Range Event in Atlanta with three American Tour de Sol vehicles on day 4, showing comparable performance from the Kineticar $(7.83 \mathrm{~km} / \mathrm{kWh})$ with the UCF vehicle $(6.56 \mathrm{~km} / \mathrm{kWh})$. Two othe American Tour de Sol conversion vehicles are also in the table to show that many vehicles performed much better than this at similar speeds.

Although the efficiency numbers generated at the different events are not directly comparable, they establish benchmarks against which existing and future EVs will be judged. Besides being tools for evaluating the development of EVs over the road and on closed courses, they set a standard for which vehicle designers and student engineers can aim. However, besides the energy economy of EV operation, the overall energy economy of EVs will be affected by the efficiency of their charging systems, as will be discussed in the next section. 


\section{Energy Charging Loss Factors and Their Effect on} Overall Electric Vehicle Efrciency

As part of the charging facilities constructed for the HEV Challenge provided by Detroit Edison, individual charging rtations were equipped with meters to measure the amount of $\mathrm{AC}$ line energy used by the HEVs to recharge their batteries after a full day of testing. The vehicles had six hours of recharging time, between $11 \mathrm{PM}$ and $5 \mathrm{AM}$. This energy was recorded and then compared to the reading on the meters in the vehicles which recorded the amount of energy that reached the vehicles' traction batteries. The difference between the line energy and the energy that reached the battery pack determined the charging efficiency of the HEVs, and established a charging loss factor as the ratio of line energy to the energy that entered the battery pack $|5|$. This loss factor, which was always greater than 1, was used to calculate the total electrical energy used by the HEVs for scoring the Energy Efficiency Event.

Table 2. Loss factors and Charge Efficiencies, Dearborn

\begin{tabular}{|c|c|c|}
\hline Ground-Up Class & Loss Factor & \% Effic \\
\hline Cal Poly - San Louis Obispo & 1.21 & 82.4 \\
\hline Cornell University & 1.67 & 60.1 \\
\hline Lawrence Technical Univ. & 2.93 & 34.1 \\
\hline Michigan State Univ. & 1.75 & 57.3 \\
\hline Univ. Cal - Davis & 2.16 & 46.3 \\
\hline Univ. of Tulsa & 3.23 & 31 \\
\hline Average & 2.16 & 46.3 \\
\hline \multicolumn{3}{|l|}{ Conversion Class } \\
\hline Cal State - Northridge & 2.14 & 46.8 \\
\hline Colorado School of Mines & 2.2 & 45.4 \\
\hline Colorado State Univ. & 3.23 & 31 \\
\hline Concordia Univ. & 3.23 & 31 \\
\hline Seattle Univ. & 1.09 & 91.5 \\
\hline Stanford Univ. & 1.48 & 67.5 \\
\hline U.S. Naval Academy & 3.23 & 31 \\
\hline Univ. of Alberta & 2.3 & 43.5 \\
\hline Univ. Illinois & 2.53 & 39.6 \\
\hline Weber State Univ. & 1.68 & 59.6 \\
\hline Average & 2.31 & 43.3 \\
\hline
\end{tabular}

The loss factors illustrated in Table 2 show that the efficiencies of the electric vehicle charging systems in use at the HEV Challenge cover a wide range from a modest $31 \%$ to a respectable $91.5 \%$. Vehicles for which a loss factor was not available used the average loss factor from all vehicles, and are not shown in Table 2. With an average value of $46 \%$ for the Ground-Up class and an average of $43 \%$ for the Conversion class, it is clear that charging inefficiencies detract from the otherwise impressive on-road electrical energy efficiency of EVs and HEVs. If these results are representative of typical charging technologies employed today, improving charging efficiencies is an area where more attention should be focused. The results show that on-board vehicle recharging systems with over $90 \%$ efficiency already are available; the selection of more efficient charging equipment and strategies should be adopted by EV and HEV designers. In addition, these results show that in order to fully understand the energy utilization of EVs and HEVs, their total electricity usage, including charging loss factors, needs to be incorporated into any assessment of their economic and environmental costs.

\section{FUTURE ACTIVITIES}

DOE will continue to support ERCs and collect data from them in 1994. Data on more types of EVs, including pre-production prototypes from major manufacturers, will be collected with plans to perform dynamometer efficiency testing as well as over-the-road and closed-course testing of EVs. To better understand HEVs, DOE, through the National Renewable Energy Laboratory, will be developing more sophisticated onboard data acquisition systems for the 1994 HEV Challenge. Additional information on HEV operating characteristics is planned to be collected to better characterize the performance levels and help determine the most promising components and vehicle configurations. The results from next year's competitions will also enable meaningful comparisons to be made with the performance data collected in 1993.

\section{CONCLUSIONS}

The electrical energy from the 1993 electric and hybrid vehicle competitions was measured with a custom-built digital meter installed in every vehicle. As expected, the mass of the vehicle has been shown to have a significant effect on vehicle energy efficiency. Data from the Atlanta competition has also demonstrated that mass becomes even more critical in designing new vehicles as the vehicles become more energy efficient. The average energy economy for the three competitions analyzed in this paper was $7.0 \mathrm{~km} / \mathrm{kWh}$, with the highest energy economy recorded during any event being $14.2 \mathrm{~km} / \mathrm{kWh}$. DOE will continue to sponsor engineering research competitions for high schools, vocational schools, community colleges, and universities for the purposes of educating students in the advanced transportation field and collecting data to demonstrate the current capabilities of electric and hybrid vehicles. 


\section{REFERENCES}

1. Wills, R., "Technical Report for 1993 American Tour de Sol," Northeast Sustainable Energy Association Conference, Greenfield, MA, 1993.

2. Proctor, R., "Catching the Dream," Home Power \#37, October/November 1993.

3. Cruising Equipment Co., "Installation Manual: KiloWatt-Hour+ Meter," Seattle, WA, February 1993.

4. Fleming, A., "Putting Fuel on the Line, Weight Reduction is Key to Achieving Tomorrow's Rules for Fuel Economy," Automotive News, November 29, 1993.

5. Ford Motor Company, 1993 Hybrid Electric Vehicle Challenge, Rules and Regulations, Ford Motor Company, Dearborn, MI, June 1993.

6. Lovins, A. B., Barnett, J. W., Lovins, L. H., "Supercars, the Coming Light-Vehicle Revolution," European Council for an Energy-Efficient Economy, Rungstedgard, Denmark, June 1993.

7. Office of Technology Assessment, Improving Automobile Fuel Economy: New Standards, New Approaches, OTA-E-504, U.S. Congress, Washington DC, 1991.

8. Adler, U., Automotive Handbook, 2nd Edition, Robert Bosch GmbH, Federal Republic of Germany, 1986.

9. Brasch, P., "A Precision DC Energy Monitor for Electric Vehicles," WESCON/93 IEEE Conference Proceedings, 1993.

10. Centre for Analysis and Dissemination of Demonstrated Energy Technologies, Electric Vehicle Directory, Electric Vehicle Progress, New York, NY, October 1991. 
Table A1. 1993 APS Solar \& Electric 500 Vehicle Data, Phoenix

\begin{tabular}{|c|c|c|c|c|c|c|}
\hline School & $\begin{array}{l}\text { Mass } \\
\text { (kg) }\end{array}$ & $\begin{array}{l}\text { Vehicle } \\
\text { Make }\end{array}$ & Model/Year & \begin{tabular}{|c|} 
Motor \\
Manufact.
\end{tabular} & $\begin{array}{l}\text { Controller } \\
\text { Manufact. }\end{array}$ & $\begin{array}{c}\text { Battery } \\
\text { Manufact. }\end{array}$ \\
\hline Agua Fria & 1,290 & Volkswagen & Rabbit/1982 & $\mathrm{GE}$ & $\mathrm{GE}$ & U.S. Batteries \\
\hline Cactus & 1,487 & Datsun & $240 / 1974$ & $\mathrm{GE}$ & GE & Trojan \\
\hline Camelback & 1,645 & Chevrolet & S10 Pickup/1985 & GE & GE & U.S. Batteries \\
\hline Carl Hayden \#13 & 1,459 & Toyota & Corolla/1978 & $\mathrm{GE}$ & GE & Exide \\
\hline Carl Hayden \#36 & 1,432 & Volkswagen & Rabbit/1980 & GE & Curtis & Exide \\
\hline Carl Hayden \#69 & 1,349 & Volkswagen & Dasher/1979 & GE & GE & Exide \\
\hline Chapparral & 1,481 & Chevrolet & Corvair/1965 & GE & GE & Trojan \\
\hline Cortez & 1,415 & Ford & Escort/1982 & GE & GE & Trojan \\
\hline East Valley Inst. & 1,481 & Chevrolet & LUV Pickup/1979 & $\mathrm{GE}$ & GE & Douglas \\
\hline Farmington & 1,471 & Datsun & $280 Z / 1976$ & GE & GE & Caterpillar \\
\hline Holbrook & 1,367 & Ford & Festiva/1988 & GE & GE & Trojan \\
\hline Marcos de Niza \#93 & 1,509 & Ford & Courier Pickup/1974 & GE & GE & Trojan \\
\hline Marcos de Niza \#94 & 1,451 & Datsun & Pickup/1978 & Curtis & Curtis & Trojan \\
\hline McClintock & 1,323 & Ford & Mustang/1980 & GE & $\mathrm{GE}$ & Trojan \\
\hline Mountain View & 1,345 & Chevrolet & Cavalier/1984 & Adv. DC & Curtis & Trojan \\
\hline North & $>2,300$ & Dodge & Pickup(1/2-ton)/1980 & GE & $\mathrm{GE}$ & Enerdyne \\
\hline Page & 1,462 & Ford & Escort/1984 & GE & GE & Trojan \\
\hline Palo Verde & 1,517 & Ford & Courier Pickup/1981 & GE & GE & Trojan \\
\hline Paradise Valley & 1,464 & Ford & Tempo/1988 & Adv. DC & Curtis & Champion \\
\hline Shadow Mountain & 1,307 & Chevrolet & Chevette/1979 & GE & GE & Trojan \\
\hline Snowflake & 1,196 & Honda & Civic/1982 & GE & GE & Power Battery \\
\hline South Mountain & 1,426 & Chevrolet & Citation/1980 & GE & GE & GNB \\
\hline St. Johns & 1,334 & Chevrolet & Chevette/1977 & Adv. DC & Curtis & Trojan \\
\hline Sunnyside & 1,533 & Chevrolet & LUV Pickup/1978 & Adv. DC & Curtis & Trojan \\
\hline Window Rock & 1,409 & Ford & Escort/1983 & $\mathrm{GE}$ & GE & Douglas \\
\hline
\end{tabular}

Table A2. 1993 Clean Air Grand Prix Vehicle Data, Atlanta

\begin{tabular}{|l|c|c|c|c|c|c|c|}
\hline \multicolumn{1}{|c|}{ School } & $\begin{array}{c}\text { Mass } \\
(\mathbf{k g})\end{array}$ & Make & Model & $\begin{array}{c}\text { Battery } \\
\text { Model }\end{array}$ & $\begin{array}{c}\text { Bus } \\
\text { Voltage }\end{array}$ & $\begin{array}{c}\text { No. of } \\
\text { Batt. }\end{array}$ & $\begin{array}{c}\text { Cell } \\
\text { Voltage }\end{array}$ \\
\hline Alcorn State & 1,082 & VW & Rabbit & DC-78 & 120 & 10 & 12 \\
\hline Berea College & 1,329 & Ford & EXP & 5 SHP & 120 & 10 & 12 \\
\hline Clemson & 1,493 & VW & Rabbit & T-145 & 120 & 20 & 6 \\
\hline Daytona Beach C.C. & 1,250 & Chevy & Chevette & 5 SHP & 126 & 10 & 12 \\
\hline Duke University & 1,023 & VW & Karmann-Ghia & TH19 & 96 & 8 & 12 \\
\hline Fort Valley State College & 1,110 & Honda & Civic & 27TMH & 108 & 9 & 12 \\
\hline Kentucky Adv. Tech & 1,300 & Hyundai & Excel GLS & TMH-27 & 120 & 10 & 12 \\
\hline Kentucky Tech & 1,595 & Chevy & Chevette & T-145 & 120 & 20 & 6 \\
\hline Louisiana Tech & 1,695 & VW & Rabbit & J305 & 120 & 20 & 6 \\
\hline Univ. of Central Florida & 1,703 & Ford & Mercury Lynx & T-145 & 120 & 20 & 6 \\
\hline
\end{tabular}


Table A3. Ground-Up 1993 HEV Challenge Vehicle Data, Dearborn

\begin{tabular}{|l|c|c|c|c|c|c|c|c|}
\hline \multicolumn{1}{|c|}{ School } & $\begin{array}{c}\text { Mass } \\
(\mathbf{k g})\end{array}$ & $\begin{array}{c}\text { Fuel } \\
\text { Type }\end{array}$ & $\begin{array}{c}\text { HEV } \\
\text { Strategy }\end{array}$ & $\begin{array}{c}\text { Battery } \\
\text { Type }\end{array}$ & APU & $\begin{array}{c}\text { Electric } \\
\text { Motor }\end{array}$ & Controller & $\begin{array}{c}\text { Battery } \\
\text { Charger }\end{array}$ \\
\hline Cal. Poly., Pomona & 1,248 & E100 & Series & Pb-Acid & Geo Metro & Adv. DC & $\mathrm{n} / \mathrm{a}$ & student built \\
\hline Cal. Poly., San Luis Obispo & 1,223 & Gasoline & Parallel & Pb-Acid & Geo Metro & Solectria & Solectria & student built \\
\hline Cornell University & 1,155 & M85 & Series & Pb-Acid & Briggs \& S. & Solectria & Solectria & Lester Elect. \\
\hline Lawrence Tech. Univ. & 1,650 & Gasoline & Parallel & Pb-Acid & Geo Metro & Magnetek & Square & K \& W Engr. \\
\hline Michigan State Univ. & 1,478 & Gasoline & Series & NiMH & Geo Metro & GE & Magnetek & $\mathrm{n} / \mathrm{a}$ \\
\hline New York Inst. of Tech. & $\mathrm{n} / \mathrm{a}$ & $\mathrm{M} 85$ & Series & Pb-Acid & Kawasaki & $\mathrm{n} / \mathrm{a}$ & $\mathrm{n} / \mathrm{a}$ & Solar Car Co. \\
\hline UC Davis & 1,062 & Gasoline & Parallel & NiCad & Briggs \& S. & Unique & Unique & Solectria \\
\hline UC Santa Barbara & 1,401 & El00 & Parallel & Pb-Acid & Suzuki & Solectria & Solectria & n/a \\
\hline Univ. of Idaho/Washington & 1,983 & Gasoline & Series & Pb-Acid & Kohler & AC Prop. & AC Prop. & AC Prop. \\
\hline University of Tennessee & 1,233 & Gasoline & Series & Pb-Acid & Kohler & Unique & Motorola & Goodall \\
\hline Univ. of Texas, Arlington & 787 & M 85 & Parallel & NiCad & Honda & Solectria & Solectria & Solectria \\
\hline University of Tulsa & 1,741 & Gasoline & Series & Pb-Aid & Honda & Baldor & Baldor & student built \\
\hline
\end{tabular}

Table A4. Escort Conversion 1993 HEV Challenge Vehicle Data, Dearborn

\begin{tabular}{|c|c|c|c|c|c|c|c|c|}
\hline School & $\begin{array}{l}\text { Mass } \\
\text { (kg) }\end{array}$ & $\begin{array}{l}\text { Fuel } \\
\text { Type }\end{array}$ & $\begin{array}{c}\text { HEV } \\
\text { Strategy }\end{array}$ & $\begin{array}{c}\text { Battery } \\
\text { Type }\end{array}$ & APU & $\begin{array}{c}\text { Electric } \\
\text { Motor }\end{array}$ & Controller & $\begin{array}{l}\text { Battery } \\
\text { Charger }\end{array}$ \\
\hline Cal. State, Northridge & 1,489 & Gasoline & Series & Pb-Acid & Kawasaki & Unique & Unique & K \& W Engr. \\
\hline Colorado School of Mines & 1,614 & E100 & Series & $\mathrm{NiCad}$ & Suzuki & Adv. DC & Curtis & ByCan \\
\hline Colorado State Univ. & 1,722 & Gasoline & Parallel & $\mathrm{Pb}$-Acid & Kawasaki & Unique & Unique & Good-All Elec \\
\hline Concordia University & 1,671 & Gasoline & Both & $\mathrm{Pb}$-Acid & Briggs \& S. & Adv. DC & Curtis & $\mathrm{n} / \mathrm{a}$ \\
\hline Jordan College Energy Inst. & 1,694 & Gasoline & Parallel & $\mathrm{Pb}$-Acid & Kawasaki & Adv. DC & Curtis & student built \\
\hline Pennsylvania State & 1,966 & Gasoline & Parallel & $\mathrm{Pb}$-Acid & Geo Metro & Solectria & Solectria & Good-All \\
\hline Seattle University & 1,715 & Gasoline & Parallel & $\mathrm{Pb}$-Acid & Geo Metro & Unique & Unique & Good-All \\
\hline Stanford University & 1,660 & Gasoline & Series & $\mathrm{Ni}-\mathrm{Cad}$ & Honda & Stanford & FMC & Solectria \\
\hline Texas Tech. University & 1,824 & E100 & Parallel & Pb-Acid & Kawasaki & Solectria & custom & Solar Car Co. \\
\hline US Naval Academy & 1,717 & Gasoline & Series & Pb-Acid & Briggs \& S. & GE & Curtis & New Concepts \\
\hline University of Alberta & 1,633 & Gasoline & Parallel & $\mathrm{NiCad}$ & Suzuki & Solectria & Solectria & student built \\
\hline UC Irvine & 1,448 & M85 & Parallel & Pb-Acid & Suzuki & Electra-Gear & Emerson & Lester Elec/ \\
\hline University of Illinois & 1,643 & E100 & Series & Pb-Acid & Kawasaki & Magnatek & Magnatek & n/a \\
\hline University of Wisconsin & 1,719 & Gasoline & Series & $\mathrm{Pb}$-Acid & Kohler & Electric App. & Indramat & $\mathrm{n} / \mathrm{a}$ \\
\hline Washington Univ., St. Louis & $\mathrm{n} / \mathrm{a}$ & E100 & Parallel & $\mathrm{Pb}$-Acid & Briggs \& S. & Adv. DC & custom & $\mathrm{n} / \mathrm{a}$ \\
\hline Wayne State University & 1,848 & Gasoline & Parallel & Pb-Acid & Ford Escort & Garret & GE & $\mathrm{n} / \mathrm{a}$ \\
\hline Weber State University & 1,725 & Gasoline & Parallel & Pb-Acid & Ford Escort & Adv. DC & Curtis & Indust. Batt. \\
\hline West Virginia University & 1,652 & M85 & Series & Pb-Acid & Kawasaki & Adv. DC & Curtis & Cybertronics \\
\hline
\end{tabular}


Table A5. 1993 American Tour de Sol Vehicle Data

\begin{tabular}{|l|c|c|c|c|l|c|}
\hline \multicolumn{1}{|c|}{ Vehicle Name } & $\mathbf{k g}$ & GU/Conv & Battery Type & $\begin{array}{c}\text { Battery } \\
\text { Capacity }\end{array}$ & \multicolumn{1}{c|}{ Motor Type } & $\begin{array}{c}\text { Regen. } \\
\text { Braking }\end{array}$ \\
\hline Aztec & 363 & GU & Lead Acid & 6.8 & DC Brushless & Y \\
\hline C-M Sunpacer & 464 & GU & Lead Acid & 9 & DC & N \\
\hline Chevy S-10 pjt. E & 1,858 & Conv. & Lead Acid & 27.6 & DC & - \\
\hline Delto Fiero SE & 1,533 & Conv. & Lead Acid & 10.6 & DC & Y \\
\hline Electric Jewel & 1,272 & Conv. & Lead Acid & 17.4 & DC Series & N \\
\hline Electric Lizzie & 989 & GU & Lead Acid & 1.6 & DC Series Wound & N \\
\hline Electric Taxi & 1,312 & Conv. & Lead Acid & 22 & DC & N \\
\hline Envirocycle & 242 & Conv. & Lead Acid & 0.94 & DC Series Wound & N \\
\hline Envirocycle II & 751 & Conv. & Lead Acid & 1.09 & DC Series & N \\
\hline Genesis I & 1,683 & Conv. & Lead Acid & 11.9 & DC & Y \\
\hline Kineticar & 1,529 & Conv. & Lead Acid & 22.2 & DC Series & Y \\
\hline Potential Difference & 1,186 & Conv. & Lead Acid & 18 & DC Series & Y \\
\hline Rham Rod & 1,457 & Conv. & Lead Acid & 17.4 & DC & Y \\
\hline Solar Bolt & 1,312 & Conv. & Lead Acid & 22 & DC & N \\
\hline Solar Bullet & 557 & GU & Lead Acid & 6.8 & DC Wire Wound & N \\
\hline Solar Flair & 1,478 & Conv. & Lead Acid & 22 & DC & N \\
\hline SUNGO & 595 & GU & Lead Acid & 7.2 & DC Brushless & Y \\
\hline T-Star & 1,125 & Conv. & Zinc Bromine & 21.6 & AC Induction & Y \\
\hline Viking 21 & 858 & GU & NiCad & 5.7 & Unique Mobility & Y \\
\hline
\end{tabular}


Table A6. 1993 Event Data Atlanta, Phoenix, and Dearborn

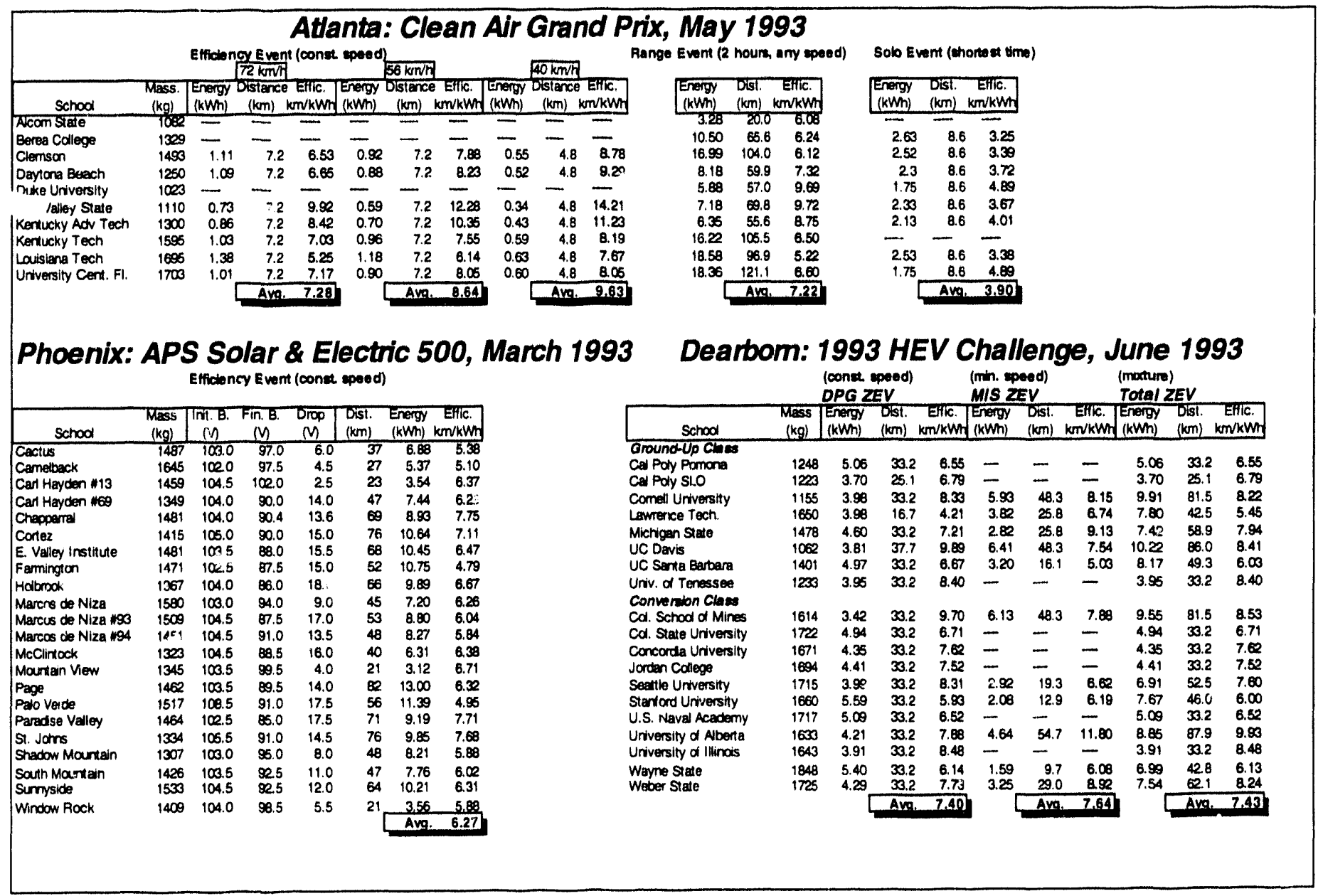

Table A7. Representative 1993 American Tour de Sol and Atlanta vehicle data comparison

\begin{tabular}{|l|c|c|c|c|c|c|c|c|c|c|c|}
\hline Vehicle Name & $\begin{array}{c}\text { Mass } \\
(\mathbf{k g})\end{array}$ & $\begin{array}{c}\text { Vehicle } \\
\text { Model }\end{array}$ & $\begin{array}{c}\text { Energy } \\
\mathbf{( k W h}\end{array}$ & $\begin{array}{c}\text { Dist. } \\
\mathbf{( k m})\end{array}$ & $\begin{array}{c}\text { Leg } \\
\text { Time } \\
(\mathbf{h r s})\end{array}$ & $\begin{array}{c}\text { Avg. } \\
\text { Speed } \\
\mathbf{( k m} / \mathbf{h})\end{array}$ & $\begin{array}{c}\text { Energy } \\
\text { Economy } \\
(\mathbf{k m} / \mathbf{k W h})\end{array}$ & $\begin{array}{c}\text { Battery } \\
\text { Type }\end{array}$ & $\begin{array}{c}\text { Motor } \\
\text { Manuf. }\end{array}$ & $\begin{array}{c}\text { Motor } \\
\text { Type }\end{array}$ & Controller \\
\hline $\begin{array}{l}\text { Univ. of Central } \\
\text { Florida * }\end{array}$ & 1,710 & $\begin{array}{c}\text { Mercury } \\
\text { Lynx }\end{array}$ & 18.36 & 120.4 & 2 & 60.2 & 6.56 & Pb-Acid & G.E. & $\begin{array}{c}\text { DC } \\
\text { Series }\end{array}$ & G.E. \\
\hline Kineticar & 1,530 & VW Rabbit & 17.77 & 139.2 & 1.87 & $55.2^{* *}$ & 7.83 & Pb-Acid & Adv. DC & $\begin{array}{c}\text { DC } \\
\text { Series }\end{array}$ & Curtis \\
\hline Electric Jewel & 1,272 & Geo Metro & 13.04 & 156.8 & 1.96 & $52.7^{* *}$ & 12.1 & Pb-Acid & Prestolite & $\begin{array}{c}\text { DC } \\
\text { Series }\end{array}$ & Curtis \\
\hline T-Star & 1,125 & Geo Metro & 10.27 & 227.2 & 1.89 & $54.6^{* *}$ & 22.26 & $\mathrm{Zn-Br}$ & Solectria & $\begin{array}{c}\text { AC } \\
\text { Induction }\end{array}$ & Solectria \\
\hline
\end{tabular}

* from the Atlanta competition

** Based on the American Tour de Sol day 4 for the leg length of $103 \mathrm{~km}$ 
